\section{International Scientific Journal Theoretical \& Applied Science}

\author{
p-ISSN: 2308-4944 (print) e-ISSN: 2409-0085 (online) \\ Year: $2017 \quad$ Issue: $04 \quad$ Volume: 48 \\ Published: $30.04 .2017 \quad$ http://T-Science.org
}

\author{
Kamoliddin Mirzaahmedov \\ Senior teacher \\ Department of Theory and Practice of Democratic \\ State Construction \\ Faculty of social sciences \\ National University of Uzbekistan \\ Tashkent, Uzbekistan
}

SECTION 22. Policy. Innovations. Theory, practice and methods.

\title{
THEORY AND MECHANISMS OF MODERN PUBLIC ADMINISTRATION
}

Abstract: This article is devoted to the activity of offices in the system of state governing, their structure, the role and place in organization of state governing, as well as the problems connected with organizing of offices in the accordance with the structure of state building are considered.

Key words: tradition, mechanism, functions of state management, democracy, the system of management of the state, administrative reform, national benefit, political and legal institution, state decision, executive authority, social institution.

Language: Russian

Citation: Mirzaahmedov K (2017) THEORY AND MECHANISMS OF MODERN PUBLIC ADMINISTRATION. ISJ Theoretical \& Applied Science, 04 (48): 90-93.

Soi: http://s-o-i.org/1.1/TAS-04-48-16 Doi: crossef https://dx.doi.org/10.15863/TAS.2017.04.48.16

\section{ТЕОРИЯ И МЕХАНИЗМЫ СОВРЕМЕННОГО ГОСУДАРСТВЕННОГО УПРАВЛЕНИЯ}

Аннотация: В данной статье представления деятельность учреждений в системе государственного управления, их структура, роль и место в организации государственного управления, а также затронуть проблемы связанные с организацией учреждений в соответствии со структурой государственного строительства.

Ключевые слова: традиция, аппарат, функции государственного управления, демократия, государственная система управления, административная реформа, национальная польза, исполнительная власть, правовое государство, государственное решение, социальный институт.

\section{Introduction}

За последние несколько десятилетий во многих странах мира проведены крупномасштабные реформы, направленные на повышение эффективности государственного управления. Большинство современных проблем социально-экономического развития в значительной степени связано с реализацией принятых органами государственной власти экономических, социальных и политических решений, направленных на дальнейшее улучшение социально-экономической ситуации в стране, обеспечение национальной безопасности. Это связано с:

$\square$ изменением статуса и функций государственной службы, качественно иным уровнем «открытости» органов государственной власти;

появлением

взаимодействия

новых

форм исполнительной власти;

переориентацией

государственной службы на нужды граждан, отстаиванием их потребностей и интересов, корректированием в соответствии с этим планов, программ и проектов собственной деятельности;

обеспечением равновесия между государственными и корпоративными интересами;

демократическим контролем над функционированием системы административного управления;

процессами

управления, делегирования ответственности снизу и др. децентрализации функций и 


\section{Materials and Methods}

Государственное управление - это целенаправленное организующее воздействие государства (через систему ее органов и должностных лиц) на общественные процессы, отношения и деятельность людей. В государственном управлении используются разнообразные материальные, финансовые, интеллектуальные и информационные ресурсы. Процесс государственного управления состоит из множества управленческих решений и действий и рассматривается как система. Система, по определению А.В.Пикулькина, - это множество элементов, частей, подсистем, которые образуют целостность, единство [1].

А по утверждению Н.И.Глазуновой, «без свойств системности госуправление не может состояться. В нем задействовано множество государственных органов и общественных структур, большое число должностных лиц и иных служащих, миллионы людей. И только системность может придать государственному управлению согласованность, координацию, субординацию, целеустремленность, рациональность, эффективность» [2].

Системный характер государственного управления заключается в обеспечении единства распорядительного (командноадминистративного) и партнерского (социальноконсолидированного) начал в практике регулирования социальных отношений и процессов [3].

Из анализа существующих точек зрения на систему государственного управления следует ее определение: это определенная совокупность иерархически связанных между собой органов политической власти и управления, во взаимодействии реализующих управление государственной сферой экономики и социальной жизни и обеспечивающих исполнение законов, конституционно установленных прав и свобод граждан.

Современная концепция государственного управления концентрирует внимание на политическом плюрализме в процессе принятия решений, делегировании полномочий на нижние уровни управленческой иерархии, более сбалансированном распределении власти, ответственности и подотчетности, развитии и расширении гражданского участия. Данная концепция предусматривает децентрализацию управления за счет расширения полномочий и ответственности органов местного самоуправления. Основная задача правительства заключается в том, чтобы предоставить местным сообществам возможность самостоятельно решать свои проблемы и контролировать качество предоставляемых публичных услуг.
Основополагающим в государственном управлении является уяснение роли и места человека и общества как объектов управления. Всякое управление проявляется во взаимодействии субъекта и объекта управления. Интенсивность прямой и обратной связи зависит от вида и характера субъекта и объекта управления. По этому критерию можно различать демократический и авторитарный характер государственного управления. Если преобладают прямые связи управления (командная информация), а механизм обратной связи слабо развит или практически блокирован, - можно говорить об авторитарном управлении. Если механизм обратной связи хорошо развит наряду с прямой, - можно говорить о демократическом управлении.

Опыт реформ государственного управления в европейских странах показывает, что пределы децентрализации обусловлены спецификой отношений и потенциалом местного самоуправления. Политическая децентрализация и коммерциализация публичных услуг в Англии, повышение роли коммун и постепенный переход к рыночным отношениям в управлении Германии, административные реформы и активизация местных сообществ во Франции все эти процессы отражают ту или иную модель децентрализации, на которые ориентируются другие европейские страны [4].

По характеру взаимоотношений центра (центральных органов власти) и регионов (органов власти национально-территориальных и административно-территориальных единиц) различают субординационное и координационное управление.

Координационное управление реализуется в форме федерации или конфедерации, когда наряду с едиными центральными органами власти существуют и периферийные, обладающие полной или частичной самостоятельностью.

Субординационное управление базируется на административном подчинении периферии центру, воздействии на нижестоящие органы управления, принуждении к выполнению команд, поступающих из вышестоящих органов управления, что характерно для унитарных государств.

По критерию использования форм собственности выделяют: региональное (субъектно-федеральное), муниципальное и частное (корпоративное) управление. По воздействию на управляемый объект выделяют отраслевое (функциональное) и территориальное управление.

Отраслевое управление предполагает наличие вертикали соподчиненности от центра до предприятия. Оно реализуется через отраслевые 
министерства, которые осуществляют единую техническую политику в отрасли, обеспечивают необхдимые внутриотраслевые и межотраслевые пропорции. При переходе к постиндустриальному развитию отмечается снижение роли отраслевого управления, так как развитие высоких технологий требует межотраслевого управления.

Территориальное управление направлено на рациональное размещение производства, углубление специализации и комплексное развитие регионов, выравнивание уровней их экономического и социального развития. Оно обеспечивается разграничением объемов полномочий между федеральными, региональными и местными органами власти.

В зависимости от масштаба временных рамок управление подразделяется на стратегическое, тактическое и оперативное.

Стратегическое управление - определяет долгосрочную ориентацию по вопросам развития общества в целом или по отдельным направлениям, сферам, объектам, территориям, намечает цели, задачи, стратегию развития общества и задает направление деятельности каждому звену управления. Основой стратегического управления являются стратегические планы, концепции развития и другие документы, отражающие постановку и методы достижения долгосрочных целей.

Различают стратегии отраслевые: развитие наукоемких отраслей, использование ресурсосберегающих технологий; функииональные: подавление инфляции, привлечение инвестиций; общеполитические: стабилизация, перестройка, социальноориентированная политика и др.

Тактическое управление - конкретные действия по реализации намеченных целей. Это краткосрочное управление, при котором на базе имеющейся информации происходит постоянное сравнение показателей стратегического плана с достигнутыми результатами за определенный период. Иногда происходит корректировка некоторых показателей стратегического плана, пересматриваются какие-либо цели, если выявляется действие ранее неучтенных факторов.

Оперативное управление - призвано решать текущие или возникающие в результате нежелательных отклонений задачи. При этом ставятся конкретные, количественно измеряемые ориентиры и используется ситуационный подход, при котором выбирается приемлемый вариант исходя из сложившихся условий.

Выделяют также такой специфический вид ситуационного управления, как антикризисное управление - вводится для предупреждения и проведения процедуры банкротства предприятий; является принудительным и внешним, так как осуществляется органами, входящими в иную чем предприятие систему, включает управление через арбитражных и конкурсных управляющих, a также управляющих предприятиямидолжниками по договору подряда.

Для сохранения конкурентоспособности предприятий иногда вводится доверительное управление, которое предполагает отделение функций владения от функций управления, осуществляется лицами по договору с органами государственного управления, трансформируется в профессиональное управление через специальных управляющих. Отношения с государством строятся не на властном подчинении, а на формальном равенстве сторон на основе договора [5].

Таким образом, система государственного управления весьма ограничена, ее элементы многомерны, многообразны, способны к саморазвитию, являются частью целого.

\section{Conclusion}

В заключении можно сказать, что понятия государство и общество взаимосвязаны. Потому что, социальная жизнь людей обладает обширной свободой и самоуправлением. Эта граница социальной свободы определяется социальными институтами и государством. То есть, государство принимая законы во всех сферах жизни людей основывает моральные, правовые нормы и обеспечивает контроль над ними. Это состояние, оценивается как «распространение государственного управления в обществе». Механизм управления не сводится только к набору методов и рычагов управленческого воздействия на социально-экономические процессы. Управленческое воздействие составляет лишь одну сторону механизма управления. Главное же содержание его определяется целевым предназначением системы, целевыми функциями каждого элемента и его взаимодействиями с другими элементами системы государственного управления. Основываясь на государственное управление, понятие госуправления, на его составляющие элементы, государственные органы, на свойства госорганов, на принцип разделения власти как организационный принцип организации работы государственного аппарата и на действие этого принципа, а также, на плодотворное действие государственного управления, нужно подчеркнуть, что государственное управление, как главный субъект социально-экономических, политических и духовных изменений прогресса общества меняется структурально и функционально. 


\begin{tabular}{l|lrl|l|ll} 
& ISRA (India) & $=\mathbf{1 . 3 4 4}$ & SIS (USA) & $=\mathbf{0 . 9 1 2}$ & ICV (Poland) & $=\mathbf{6 . 6 3 0}$ \\
Impact Factor: & ISI (Dubai, UAE) $=\mathbf{0 . 8 2 9}$ & PUHL (Russia) $=\mathbf{0 . 2 3 4}$ & PIF (India) & $=\mathbf{1 . 9 4 0}$ \\
& GIF (Australia) & $\mathbf{0 . 5 6 4}$ & ESJI (KZ) & $=3.860$ & IBI (India) & $=\mathbf{4 . 2 6 0}$ \\
& JIF & $\mathbf{1 . 5 0 0}$ & SJIF (Morocco) & $=\mathbf{2 . 0 3 1}$ & & \\
\hline
\end{tabular}

\section{References:}

1. Pikul'kin AV (2000) Sistema gosudarstvennogo upravleniya: Uchebnik dlya vuzov.-2-e izd., pererab. i dop. M.: YUNITIDANA.

2. Glazunova NI (2001) Gosudarstvennoe upravlenie kak sistema. GGU. M..

3. Mitin AN, Rassohin AV (2008) Sistemnye osnovy gosudarstvennogo i municipal'nogo upravleniya. Ekaterinburg: ID UrGYUA.

4. (2016) [Elektronnyy resurs]. k.eh.n. Rahmetulina Z.B. i mag. Ual'hanov O.E. "Sovremennye koncepcii gosudarstvennogo upravleniya", Vostochno-Kazahstanskiy gosudarstvennyy universitet im. S.Amanzholova, Kazahstan. Available: http://www.konspekt.biz/index.php?text=4232 (Accessed: 01.12.2016).

5. Naumov SY, et al. (2008) «Sistema gosudarstvennogo upravleniya» - M.: «Forum».
6. Matyash SA (2014) Informacionnye tekhnologii upravleniya: kurs lekciy. - M.: Direkt-Media. - 537 p.

7. (2014) Pravo i pravoprimenenie $\mathrm{v}$ zerkale social'nyh nauk : hrestomatiya sovremennyh tekstov. - M.: Statut. - 568 p.

8. Lapaeva MG, Lapaev SP, Kuzaeva TV (2015) Teorii prostranstvennogo i regional'nogo razvitiya: uchebnoe posobie. Orenburg: OGU.$141 \mathrm{p}$.

9. Moiseev VV (2015) Sistema gosudarstvennogo i municipal'nogo upravleniya: uchebnoe posobie. - M.: Direkt-Media. - 603 p.

10. Baynova MS, Medvedeva NV, Ryazanceva YS (2016) Osnovy gosudarstvennogo i municipal'nogo upravleniya: uchebnoe posobie. - M.: Direkt-Media. - 459 p. 


\begin{tabular}{l|lr|ll|ll} 
& ISRA (India) & $\mathbf{1 . 3 4 4}$ & SIS (USA) & $=\mathbf{0 . 9 1 2}$ & ICV (Poland) & $=\mathbf{6 . 6 3 0}$ \\
Impact Factor: & ISI (Dubai, UAE) $=\mathbf{0 . 8 2 9}$ & PUHЦ (Russia) & $=\mathbf{0 . 2 3 4}$ & PIF (India) & $=\mathbf{1 . 9 4 0}$ \\
& GIF (Australia) & $=\mathbf{0 . 5 6 4}$ & ESJI (KZ) & $=\mathbf{3 . 8 6 0}$ & IBI (India) & $=\mathbf{4 . 2 6 0}$ \\
& JIF & $\mathbf{1 . 5 0 0}$ & SJIF (Morocco) & $\mathbf{2 . 0 3 1}$ & & \\
\hline
\end{tabular}

